\title{
Drive by set interactions in a word recognition task
}

\author{
Vera R. Pezer and N. MeK. Agnew $l$
}

UNIVERSITY OF SASKATCHEWAN

\begin{abstract}
Four experiments were conducted to determine the effects of frequency, drive, set, and response competition on word recognition thresholds. The results indicated that drive, set, and frequency interacted in ways which were replicable across experimenters, and across methods of manipulating arousal (MAS and induced muscle tension).
\end{abstract}

\section{Problem}

Experimental evidence has suggested that drive, word frequency, and set are among the important variables affecting word recognition thresholds. Engler \& Freeman (1956) found that high frequency and set both led to lower thresholds, and surprisingly, that set interacted with drive in such a way that set facilitated performance for low MAS Ss and impaired performance for high MAS Ss, the greater discrepancy occurring with set neutral words. They explained the unexpected impairment demonstrated by high MAS Ss under set conditions as a function of increased response competition growing out of the random presentation of setrelevant and set-irrelevant words.

This study involved a replication and extension of the Engler \& Freeman (1956) findings. A condition involving only set relevant words was added to the design to test the Engler and Freeman results under reduced response competition conditions. Also, drive was manipulated not only by means of anxiety scale scores but also by means of brief induced muscle tension. There is almost no data involving human Ss to test the effects of using different methods of manipulating drive level on the same task.

\section{Method}

The Taylor MAS (short form) was administered to students in second-year psychology classes at the University of Saskatchewan. Cut-off points of 10 and 24 were adopted, and Ss were assigned to low, medium, and high anxiety groups respectively.

A Gerbrands Harvard-Dodge type tachistoscope was used to obtain recognition thresholds. The exposure field, consisting of a white square $7-1 / 2 \times 7-1 / 2$ in, was 22 in from S's eyes. The $8 \times 8$ in preexposure field with a fixation point (a cross $1 / 2 \times 1 / 2$ in) was 18 in from S's eyes. To facilitate the changing of exposure durations, a Hunter timer ${ }^{2}$ was wired to the tachistoscope.

In Experiments I and III, the mixed series of set relevant and irrelevant stimulus words were the same as those used by Engler \& Freeman (1956). In each experiment four groups of Ss participated in a $2 \times 2$ factorial design under the various combinations of set (animal and neutral words) and drive (high and low MAS for Experiment $I$ and high and low induced muscle tension for Experiment III). Ss serving under animal set were instructed that some of the words would be animal words, whereas the neutral set Ss were told only that words would be presented and they were to try and recognize them as quickly as possible.

Experiments II and IV were identical to Experiments I and III with the exception that only set relevant stimulus words were used. Ss serving under animal set were instructed that all the words would be animal words, whereas neutral set Ss were told only that they were being given words for recognition. In each experiment four groups of Ss participated in $2 \times 2$ factorial designs under the same combinations of set and drive as prevailed in Experiments I and III. Those Ss serving under induced muscle tension had scored between 11 and 23 inclusive on the Taylor MAS.

In all cases, the stimuli were typed in elite capitals in the center of white index cards $3 \times 5$ in. Recognition thresholds were obtained by the ascending method of limits in a manner identical to that used by Engler \& Freeman (1956). Order of presentation of stimuli was randomly determined after being balanced for frequency.

\section{Results}

Experiment I

The first experiment was generally a successful replication of the Engler \& Freeman (1956) experiment. There was a significant frequency effect ( $F=$ $34.81 ; \mathrm{df}=1,168 ; \mathrm{p}<.001)$, a significant anxiety $\mathrm{x}$ set interaction $(F=4.50 ; d f=1,56 ; p<.05)$, and a significant frequency $x$ anxiety $x$ set interaction $(F=5.08 ; d f=1,168$; $\mathrm{p}<.05)$. This interaction is displayed in Fig. 1. Low MAS Ss consistently benefited by set and high MAS Ss did not, the effect being particularly pronounced with low frequency material. This experiment did not provide the significant words and words $\mathrm{x}$ set effect obtained by Engler \& Freeman (1956).

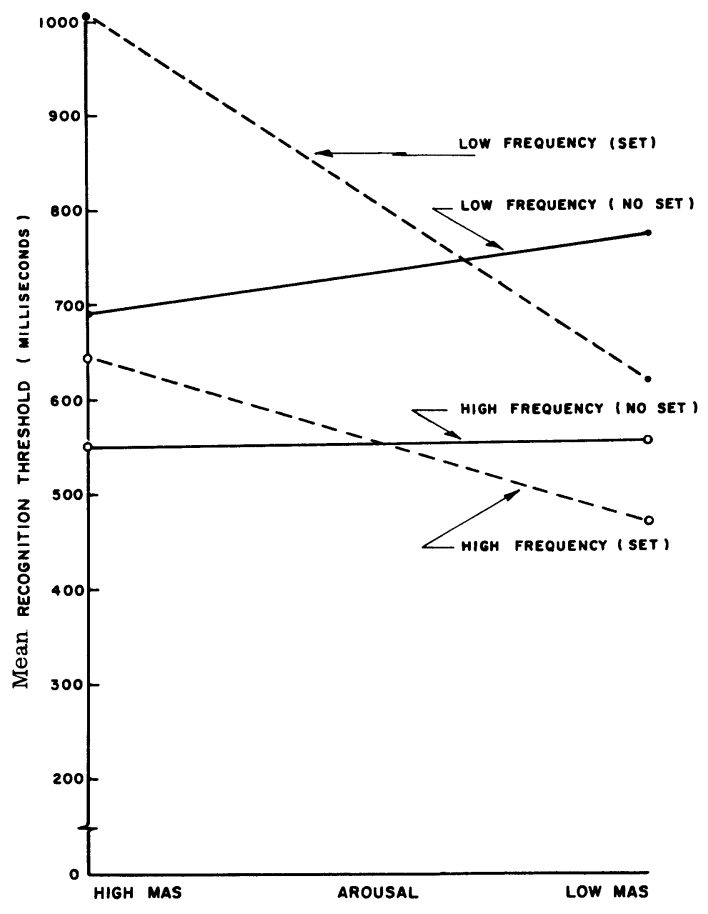

Fig. 1. Mean recognition thresholds of high and low MAS Ss on high and low frequency material under set and no-set conditions. 
Experiment II

Engler \& Freeman (1956) interpreted the impairing effects of set on high MAS Ss in terms of set leading to increased response competition under conditions where both set-relevant and set-irrelevant words were presented. In order to evaluate this explanation the second experiment was identical to the first except response competition was reduced by using only setrelevant words. The prediction was that under reduced response competition the facilitative effects of set would be particularly evident for high MAS Ss, at least initially in the series until the no-set group developed an induced set due to the homogeneity of the stimuli.

As predicted, under reduced response competition, the high and low MAS groups reversed position, with the high MAS group having lower thresholds. The difference between the two groups, however, does not reach a statistically significant level. There was a main facilitative effect of set in the firsthalf of the experiment on low frequency words $(F=5.80 ; d f=1,50 ; p<.05)$. There was also a set $x$ anxiety interaction $(F=4.99 ; \mathrm{df}=1,50$; $\mathrm{p}<.05)$ indicating marked impairment in the low MAS no-set group. 'Inis condition can perhaps be best conceived as a condition of low associative strength (low frequency words and no set) and low arousal (low MAS) leading to little response biasing, i. e., to a large number of equa!ly probable responses which is the prototype of guessing situation.

Experiment III

This experiment tested the generalizability of the Engler \& Freeman (1956) results using induced muscle tension rather than MAS scores as the means of indexing drive level. Ss briefly squeezed and released a hand dynamometer ${ }^{3}$ just prior to the display to be judged. Using this procedure, Ss are not distracted by having to squeeze the dynamometer during the presentation of the display; nevertheless, there is evidence, using physiological indices of arousal, that high arousal persists for an appreciable period after the dynamometer is released (Agnew et al, 1965).

In general, the results of this experiment mirrored those of Engler \& Freeman (1956) and of Experiment I but at a reduced level of intensity. The distributions showed the same set $\mathrm{x}$ drive interaction, where set facilitated performance for low drive Ss and impaired performance for high drive Ss. However, while the form of distribution was replicated the interaction in this experiment did not reach statistical significance. There was a significant frequency effect $(\mathrm{F}=55.04$; $\mathrm{df}=$ $1,132 ; \mathrm{p}<.001)$ consistent with the results of Experiments I and II.

\section{Experiment IV}

This experiment was a replication of Experiment II with induced muscle tension, rather than MAS scores, used as the method of manipulating drive level in a situation of low response competition. Except for a frequency effect $(F=22.17 ; \mathrm{df}=1,36 ; \mathrm{p}<.001)$ the results were non-significant.

\section{Diseussion}

Frequency and set supposedly serve a response biasing function. In these experiments stimulus frequency played a major steering function across a wide range of conditions-level of drive, types of drive, and degree of response competition in the test situation. The most evident steering effects of set were on low frequency material in Experiments I and III and early in Experiment II. Perhaps with high frequency stimuli the response probabilities are already so high that facilitative effects of other steering variables are less likely to make an appreciable difference.

In attempting to explain why high MAS Ss were not assisted by set, Engler \& Freeman (1956) postulated that set led to greater response competition than no set when set relevant and irrelevant words were presented randomly. It would presumably follow that the low MAS set group should have higher thresholds than the low MAS no-set group due to set increasing response competition. In both the Engler and Freeman experiment and in Experiments I, II and III of the present series, the reverse was true. Some additional explanation is required which helps account for this complex, yet replicable interaction. While no completely adequate explanation is as yet available the following proposal suggests an experimental line of attack.

If drive is assumed to serve a generalized priming function and to bear a multiplicative relationship with response strength (Hebb, 1955; Osgood, 1957), then under high drive the organism is strongly biased toward making well practiced responses. If high drive Ss possess a response bias toward high frequency words, then they require help in broadening the number of alternative responses in tasks where both high and low frequency words occur. Since set would lead to further response biasing, this might explain why, in a situation with response competition, high drive Ss perform more poorly under set. Conversely, low drive Ss should have a very large number of response alternatives from which to draw and would require help in narrowing the number of alternatives. Conceivably, set can serve this function for the low arousal group, and so account for their superior performance. Adequate explanation must await further experiments involving more than just two levels of word frequency and of set under high and low drive conditions.

There is a paucity of human data involving cross-drive comparisons. While different methods of inducing drive level (MAS and induced muscle tension) led to similar distributions of data in Experiments I and III involving response competition, such was not the case in Experiments II and IV when response competition was minimized. As noted by Kausler \& Trapp (1960) we require much more data on human Ss under dross-drive conditions before important generalizations can be made.

\section{References}

AGNEW, N. McK., PYKE, SANDRA, \& PYLYSHYN, Z. Absolute judgment of distance as a function of induced muscle tension, exposure time, and feedback. J. exp. Psychol., 1965, in press.

ENGLER, JEAN \& FREEMAN, J.T. Perceptual behavior as related to factors of associative and drive strength. J. exp. Psychol., $1956,51,399-404$.

HEBB, D. O. Drives and the C. N.S. (conceptual nervous system). Psychol. Rev., 1955, 62, 243-254.

KAUSLER, D. H., \& TRAPP, E。P. Motivation and cue utilization in incidental learning. Psychol. Rev., 1960, 60, 373-379.

OSGOOD, C. E. Motivational dynamics of language behavior. In M. R. Jones (Ed.), Nebraska Symposium on Motivation. Lincoln: University of Nebraska Press, 1957. Pp. 348-424.

\section{Notes}

1. Based on a thesis submitted by one of the authors (VP) in partial fulfilment of the requirements for the M. A. degree, University of Saskatchewan, 1964. This research was supported in part by grants to one of the authors (NMA) from National Institutes of Mental Health, U. S. Public Health Services (MY-3612) and Canadian National Research Council.

2. Hunter Mfg. Co., Inc., Iowa City, Iowa, U. S. A.

3. C. H. Stoelting Co., Chicago 24, Illinois, U. S. A. 